\title{
El Círculo Católico de san Martín Cid. Primeros pasos de la acción social católica en Zamora e implicación de los líderes carlistas en ella (1891-1912)
}

The Catholic Circle of San Martín Cid. The First Steps of the Catholic Social Action in Zamora and the Involvement of the Carlist leaders (1891-1912)

Miguel Ángel HERNÁNDEZ FUENTES

Doctor por la Universidad de Salamanca

miguelangelhernandez@usal.es

\begin{abstract}
In order to have a better understanding of social Catholicism in Spain, it is necessary to study various social institutions, our knowledge of which is still fragmentary. This article presents the repercussions that the Social Doctrine of the Church had in Zamora and analyzes one of its first projects: the Catholic Circle of San Martín Cid, founded in 1891, which went from being a center of instruction and recreation to a place to promote other social initiatives. Similarly, we show the involvement of the Carlists in the social projects of the Church and the relationship between social Catholicism and the Labor Movement.
\end{abstract}

Keywords: Restoration; Social Doctrine of the Church; Catholic Circles of Workers; Carlism; Zamora.
Resumen: Para un mayor conocimiento del catolicismo social en España es preciso el estudio de las obras sociales concretas cuyo conocimiento es aún fragmentario. Con este artículo se presenta la repercusión que la doctrina social de la Iglesia tuvo en Zamora y se analiza uno de sus primeros proyectos: el Círculo $\mathrm{Ca}^{-}$ tólico de san Martín Cid, fundado en 1891, que pasó de ser un centro de instrucción y recreo a convertirse en eje coordinador de otras iniciativas sociales. Asimismo, mostramos la implicación de los carlistas en los proyectos sociales de la Iglesia y la relación del catolicismo social con el movimiento obrero local.

Palabras clave: Restauración; Círculos Católicos de Obreros; Doctrina Social de la Iglesia; Carlismo; Zamora.

\section{INTRODUCCIÓN}

Pocas actividades católicas suscitaron una atención tan temprana por parte de la investigación académica ajena a los centros eclesiásticos como el catolicismo social ${ }^{1}$. Los primeros estudios en este campo comenzaron en los años cuarenta

1 Dos balances tempranos de estos estudios pueden consultarse en Feliciano MONTERO GARCÍA, El primer catolicismo social en España: estado de la cuestión, en Studia Historica. Historia Contemporánea, 2 (1984), pp. 185-192; y Josefina CUESTA BUSTILLO, Estudios sobre el catolicis- 
y, aunque estaban vinculados a instituciones eclesiásticas, formularon un análisis crítico del catolicismo social desarrollado en las décadas precedentes. Desde una mentalidad pastoral $y$, con un cierto pesimismo, los autores de la época señalaban el carácter paternalista de las obras sociales católicas, su insuficiente conciencia social y el escaso éxito logrado. Esto produjo una sensación de fracaso y generó la conocida tesis de la «apostasía de las masas»². En los años setenta, otros autores menos vinculados a los centros eclesiásticos se acercaron al sindicalismo agrario desde las corrientes historiográficas entonces en boga, muy condicionadas por el materialismo histórico ${ }^{3}$. Con el paso de los años, sus tesis fueron cuestionadas por otras publicaciones que aportaron una visión más contrastada del sindicalismo confesional ${ }^{4}$. También los Círculos Católicos de Obreros suscitaron el interés de algunos historiadores y fueron objeto de diversos estudios. Entre sus máximos exponentes figura José Andrés Gallego, cuyo análisis del catolicismo social estuvo marcado por el intento «de sacar el tema de los planteamientos propios de la historia política y de la polémica ideológica para introducirlo en una reconsideración hecha con criterios más bien institucionalistas» ${ }^{5}$. Junto a él, Feliciano Montero dedicó uno de sus primeros libros al desarrollo temprano del catolicismo social en España, donde pretendía formular un análisis ajeno al conflicto ideológico e insertarlo en una comprensión global de la actividad desarrollada por la Iglesia ${ }^{6}$.

mo social español (1915-1930). Un estado de la cuestión, en ibid., pp. 194-244. A ellos podemos sumar las publicaciones más recientes de José Manuel CUENCA TORIBIO, Catolicismo social y político en la España Contemporánea (1870-2000), (Monografías), Madrid, 2003; Feliciano MonTero, El catolicismo social en España. Balance bistorio gráfico, en Benoît PELLISTRANDI (ed.), L'histoire religieuse en France et en Espagne (coll. «Casa de Velázquez», 87), Madrid, 2004, pp. 389-409.

2 Feliciano MONTERO, «La apostasía de las masas» y la recristianización de la sociedad: las estrategias pastorales de la Iglesia española en el siglo XX, en El siglo XX balance y perspectivas. V Congreso de la Asociación de Historia Contemporánea, Valencia, 2000, pp. 391-398.

3 Juan José CASTILlo, El sindicalismo amarillo en España. Una aportación al estudio del catolicismo social español (1912-1923), Madrid, 1977; ID., Propietarios muy pobres. Sobre la subordinación política del pequeño campesino en España (La Confederación Nacional Católico-Agraria, 1917-1942), Madrid, 1979 y Josefina CUESTA BUSTILlO, Sindicalismo católico agrario en España (1917-1919), Madrid, 1978.

4 José María ARribas MaCHO, El sindicalismo agrario: un instrumento de modernización de la agricultura, en Revista de Historia Social, 4 (1989), pp. 33-52; Samuel GARRIDO HERRERO, El primer cooperativismo agrario español, en CIRIEC-España, Revista de economía pública, social y cooperativa, 44 (2003), p. 36.

5 José ANDrÉs-Gallego, Pensamiento y acción social de la Iglesia en España, Madrid, 1984, p. 401.

6 Feliciano MONTERO, El primer catolicismo social y la Rerum novarum en España (1889-1902), (Monografías de Historia Eclesiástica, 13), Madrid, 1983. 
Según ambos autores, la tesis del fracaso nacía desde una perspectiva desenfocada, pues la valoración de los resultados sobre la acción social católica debía hacerse «en función de sus propios objetivos y no de los correspondientes a otras obras sociales» ${ }^{7}$. Feliciano Montero confiaba en que esta desideologización del tema traería consigo la revitalización de los estudios sobre el catolicismo social, pero sus esperanzas no se cumplieron y, como ha señalado él mismo, los estudios que analizaron el catolicismo social «han sido bastante escasos y poco significativos» ${ }^{8}$. Junto a ellos, José Manuel Cuenca Toribio ha sido otro de los autores más fecundos en este campo, cuyos eruditos libros han mostrado los notables avances del catolicismo agrario y el fracaso del sindicalismo obrero confesional que comenzó dando pasos importantes, pero no logró alcanzar su madurez ${ }^{9}$.

En su balance historiográfico sobre el catolicismo social en Castilla y León, Enrique Berzal de la Rosa señala las carencias existentes en este campo y se lamenta de que aún no se haya superado el análisis meramente cuantitativo y organizativo para abordar aspectos cualitativos ${ }^{10}$. Con el fin de ofrecer un análisis más detallado de las consecuencias sociales y económicas del catolicismo social, el citado autor ha señalado la necesidad de tener un mayor conocimiento de cada sindicato $y$, aunque se han dado algunos pasos en el estudio de los existentes en Burgos, Palencia o Valladolid, las publicaciones son prácticamente inexistentes para el caso de Zamora ${ }^{11}$. Tampoco tenemos mucha suerte con las investigaciones locales dedicadas a la Restauración. Miguel Ángel Mateos, uno de los mejores conocedores de la provincia en este periodo, apenas dedica unas líneas a los primeros compases del movimiento obrero y pasa de puntillas sobre la acción social católica, pues, aunque traza una radiografía de la sociedad zamorana del momento, sus trabajos están más centrados en el estudio de las élites políticas y de los comportamientos electorales ${ }^{12}$. Por otra parte, el carácter inédito de la tesis de María Paz Corredera, dedicada a la beneficencia y la previsión en Zamora a comienzos del siglo XX, sustrae este trabajo al público

7 Feliciano MonTERo, El catolicismo social... [ver n. 1], p. 394.

8 Ibid., p. 392.

9 José Manuel CuenCa TORIBIO, Catolicismo social... [ver n. 1], p. 318.

10 Enrique BerZal de la Rosa, Catolicismo social en Castilla y León. Estado de la cuestión, en Alcores, 1 (2006), p. 223.

11 Ibid., pp. 218-223.

12 Miguel Ángel Mateos RodrígueZ, Historia de Zamora, tomo 3, La Historia Contemporánea, Zamora, 1995; ID., La República en Zamora (1931-1936). Comportamiento político electoral de una sociedad tradicional, Zamora, 1988. 
más interesado ${ }^{13} \mathrm{y}$ en otras publicaciones apenas dedica espacio al tema que nos ocupa ${ }^{14}$.

Con este artículo pretendemos paliar la carencia detectada por los estudiosos de la acción social católica y de la historia religiosa que reclaman una mayor exploración de los archivos locales para lograr un mejor conocimiento de la realidad $^{15}$. El análisis del Círculo Católico Obrero de Zamora nos permitirá hacer una valoración de la recepción del magisterio social pontificio y la puesta en práctica de la acción social católica lejos de los centros principales de decisión. En la mayor parte de los estudios sobre el catolicismo social se ha subrayado su carácter defensivo frente al movimiento obrero. Sin duda, el discurso contrario a las tesis socialistas estaba presente en la mayor parte de las publicaciones sociales católicas del momento, pero es preciso observar la confrontación existente entre ambos modelos en el ámbito local para sondear la repercusión que el debate ideológico o intelectual tenía entre la población local. Asimismo, el estudio de un Círculo Católico en concreto nos permitirá observar su actividad, sus prioridades, su evolución a lo largo de los años e incluso identificar a sus agentes principales.

No disponemos de muchas fuentes para ello, por lo cual, el rastreo de la prensa periódica ha sido capital para este trabajo. Los límites cronológicos que nos hemos trazado son los años 1891 y 1912. El primero viene dado por la fundación del Círculo Católico de Zamora y el segundo por la profunda transformación que este vivió en 1912, lo que supuso la renovación de su junta directiva y la asunción del liderazgo de la acción social diocesana conforme a las Normas de Acción Católica y Social en España, publicadas en 1910. Asimismo, por esas fechas, el Círculo Católico asumió un papel más beligerante con las asociaciones obreras locales, las cuales también mostraron un discurso anticlerical creciente que, en Zamora, se notó especialmente durante la celebración del primero de mayo de 1912. Comenzamos el artículo con una exposición sobre la recepción de la doctrina social en la diócesis y exponemos a continuación la fundación y desarrollo del Círculo Católico zamorano como una de las expresiones más tempranas y características de la acción social católica.

13 María Paz Corredera García, Beneficencia y previsión en Zamora, 1900-1936, Universidad de Salamanca, 1993, tesis doctoral inédita.

14 María Paz Corredera García y Josefina Cuesta Bustillo, Historia de la acción social en Zamora en el primer tercio del siglo XX, en Primer Congreso de Historia de Zamora (Actas), Zamora, 1993, pp. 531-551.

15 Miguel Ángel HeRnÁNDEZ Fuentes, La historia religiosa contemporánea en España: memoria, identidad y propuestas, en Revista Expedições: Teoria da Historia \& Historiografia, 7 (2016), pp. 179181. 


\section{RECEPCIÓN DE LA DOCTRINA SOCIAL PONTIFICIA EN ZAMORA}

El desarrollo de la doctrina social de la Iglesia en España fue tardía respecto a otros países donde ya existían algunas iniciativas sociales católicas previas a la publicación de la Rerum novarum. En su estudio sobre la recepción de la encíclica en España y el desarrollo temprano del catolicismo social en nuestro país, Feliciano Montero subrayaba el retraso del catolicismo social español y la débil recepción de la encíclica que, salvo casos aislados, no tuvo comentarios en profundidad hasta la publicación de Socialismo y anarquismo del padre Vicent. Entre las razones de este retraso, Montero destaca la lentitud del reformismo social español y la difícil adaptación del catolicismo hispano al mundo moderno dada la situación privilegiada de la que había gozado en nuestro país ${ }^{16}$. En Zamora la encíclica fue saludada por el obispo diocesano, quien publicó una pastoral invitando a su lectura. Sin embargo, Tomás Belestá no comentaba el contenido de la carta, ni desarrollaba ninguna de sus propuestas ${ }^{17}$, tan solo señalaba la vinculación de la cuestión obrera con la situación moral y religiosa y subrayaba la superioridad de la Iglesia a la hora de ofrecer una respuesta adecuada al problema:

Lo que causa extrañeza es que los flamantes reformadores y pretendidos directores de los destinos sociales, no hayan comprendido todavía las estrechas relaciones que enlazan la cuestión obrera y económica con la social y ésta con la moral y religiosa, y que, sin el concurso y las luces que derraman todas ellas, convergiendo a un solo punto, no es posible resolverla favorable y satisfactoriamente. Todavía no han comprendido que esas alteraciones pasajeras, no son más que un síntoma de la dolencia, una llamarada del volcán, una chispa de la electricidad de que está cargada la atmósfera social ${ }^{18}$.

El obispo de Zamora se movía en la línea de la mayor parte del episcopado español que solo subrayaba «la raíz religioso-moral de la cuestión social, y por tanto, la pertinencia de la intervención de la Iglesia y del papa en la búsqueda de soluciones católicas» ${ }^{19}$. En el análisis que Feliciano Montero hace de las cartas publicadas por los prelados españoles con motivo de la encíclica, se señala que la pre-

16 Feliciano MONTERo, El primer catolicismo social... [ver n. 6], pp. 401-402.

17 «No nos atrevemos a hacer comentario alguno por temor de desvirtuar la portentosa doctrina que en ella desenvuelve, con nuestra desaliñada pluma», Tomás BELEsTá, Carta pastoral sobre la cuestión obrera, en Boletín Eclesiástico del Obispado de Zamora, 29 (1891), p. 232.

18 Ibid., p. 230.

19 Feliciano MONTERO, El eco de «Rerum novarum» en España. La primera recepción, en Rerum novarum. Ecriture, contenu et réception d'une encyclique, Roma, 1997, p. 435. 
sentación hecha por Tomás Belestá es una valoración fundamentalmente genérica y global, la cual, «desde una perspectiva eminentemente donosiana, señala las raíces filosófico-religiosas del conflicto social $\gg^{20}$. Este prelado tenía tras de sí una interesante trayectoria, pues había sido rector de la Universidad de Salamanca antes de ocupar la sede zamorana y se movía en la órbita del Partido Conservador que lo había promovido al episcopado y le había conseguido un escaño en el Senado ${ }^{21}$. En 1894, con un nuevo prelado al frente del obispado zamorano, la diócesis se sumó a la peregrinación obrera a Roma con el fin de agradecer al pontífice la publicación del documento. El viaje fue un éxito con el que se quiso manifestar la capacidad de movilización de la Iglesia y la fidelidad de los obreros en su adhesión a Jesucristo, convirtiendo esta romería en una exaltación del pontificado romano que había sido desposeído de los Estados Pontificios y se consideraba «preso» en el Vaticano ${ }^{22}$.

Sin embargo, la recepción de la doctrina social de la Iglesia en la diócesis de Zamora no puede limitarse al estudio de las pastorales y documentos contenidos en el Boletín Oficial del Obispado. Desde 1897 el catolicismo zamorano contó con un órgano de expresión vinculado al carlismo local, El Correo de Zamora, que salía a la calle con el apelativo de Diario católico tradicionalista. Sus redactores eran conocidos creyentes de la ciudad, muy cercanos a la actividad pastoral del obispo Luis Felipe Ortiz, quienes lideraron diversas instituciones católicas como la Asociación del Culto Continuo o la Adoración Nocturna ${ }^{23}$. Junto a ellos estaba un grupo de influyentes sacerdotes de la ciudad que colaboraba en la línea editorial del periódico como Gregorio Rodríguez Téllez, Diego Luis y Melchor Zataraín. Sin duda, la lectura de la encíclica estaba tamizada por sus propios postulados políticos, pero el carlismo coincidía sustancialmente con la visión organicista de la sociedad que aparecía en los documentos pontificios. En el acta de Loredán de 1897, donde se sintetizaba el programa carlista, se asumía explícitamente la doctrina pontificia: «queremos protestar y redimirle llevando a la legislación la enseñanza de la más admirable encíclica de León XIII» ${ }^{24}$. Este documento nacía

20 Feliciano Montero, El primer catolicismo social..., [ver n. 6], p. 170.

21 Miguel Ángel HeRNÁNDEZ FuENTES, Obispo y candidato del Gobierno. El apoyo mutuo y la convergencia de intereses entre Tomás Belestá y el Partido Conservador, en Alcores. Revista de Historia Contemporánea, 19 (2015), pp. 259-276.

22 Boletín Eclesiástico del Obispado de Zamora, 32 (1894), pp. 62-65.

23 Miguel Ángel HeRnÁNDEZ FUENTES, La comunión reparadora. Piedad eucarística y renovación católica en Zamora durante la Restauración, en Studia Zamorensia, 15 (2016), pp. 172-173.

24 Acta de Loredán. Acta de las conferencias celebradas en el Palacio de Loredán, de Venecia, redactada por el marqués de Cerralbo y oficialmente aprobada por Carlos VII (enero 1897), en Melchor FERRER, Escritos políticos de Carlos VII, Madrid, 1957, pp. 224-225. 
en medio de un proceso de renovación del carlismo operada a mediados de los noventa por el que se trataba de renovar el partido y presentar el carlismo como una opción «real y creíble a través de una puesta al día en lo ideológico» 25 .

Respecto a la cuestión social, el discurso católico que aparecía en el periódico no mitigaba los males padecidos por los obreros. $\mathrm{Al}$ contrario, desde su postura antiliberal, estos eran descritos como una de las consecuencias del capitalismo. Precisamente, en la citada acta de Loredán se había señalado que la ley de la oferta y la demanda era culpable de la miseria sufrida por los obreros, al convertir el trabajo en mercancía y al hombre en máquina ${ }^{26}$. En esta misma línea, los redactores de El Correo de Zamora añadían un matiz religioso y moral, insistiendo en que el egoísmo de las clases pudientes y las artimañas del capitalismo eran los responsables de la cuestión obrera y los causantes de la conflictividad social promovida por el socialismo. El capitalista sin caridad, señalaba el rector del Seminario en 1904, «tardará muy poco, llevado de la ambición en convertirse en tirano de los demás capitalistas y hasta de los infelices obreros, quienes faltos de virtud y resignación por los malos ejemplos, tratarán de tomar la revancha $\gg^{27}$. Desde esta postura tradicionalista, los redactores del periódico señalaban que las reclamaciones obreras estaban justificadas en muchas ocasiones, aunque no asumieran la conflictividad que los socialistas proponían. En sus páginas se recurría a criterios morales, pero también económicos, a la hora de señalar los errores de la propuesta socialista:

No siempre ni en todo tienen razón los obreros; pero no cabe dudar que la tienen en muchas ocasiones y en gran parte de lo que piden. Lo que hay es que el remedio no está donde cree el socialismo, no está en la resistencia, que si en ocasiones es lícita, en otras no lo es; y sobre todo, si se generaliza, constituye una amenaza constante $\mathrm{y}$ un grave peligro para la paz social y hasta un perjuicio para los mismos trabajadores porque, ante esa actitud de resistencia, los capitalistas retirarán sus capitales de la industria y con ello el mal se aumentará en vez de disminuir ${ }^{28}$.

Frente al riesgo que podía suponer la violencia obrera, la respuesta que se promovía por los tradicionalistas locales estaba fundamentada en la doctrina social católica y consistía en una acción protectora por parte de las clases pudientes en favor de los menesterosos: «Como hombres y como cristianos estamos

25 Jordi CANAL, La reconversión del carlismo (1876-1931), en Julio ARóSTEgUI, Jordi CANAL y Eduardo GONZÁlez CALleja, El carlismo y las guerras carlistas. Hechos, hombres, ideas, Madrid, 2003, p. 94.

26 Acta de Loredán... [ver n. 24], p. 224.

27 El Correo de Zamora, 5-5-1904.

28 El Correo de Zamora, 19-2-1903. 
obligados a procurar el bienestar del obrero, socorriéndoles en sus necesidades físicas y sobre todo abriendo su alma a las luces fecundas de la verdad $»^{29}$. Sin abandonar este paternalismo, también se fueron asumiendo otros planteamientos que vinculaban las obras sociales con la justicia y trataban de superar una acción puramente benéfica. Así lo proponía Luis Chaves Arias en Zamora: «no solo por deberes de caridad, sino de justicia, estamos obligados a ir al pueblo» ${ }^{30}$. Tras este planteamiento estaba la pretensión de la Iglesia de lograr la redención de la clase trabajadora mediante una acción social inspirada en el magisterio pontificio. Así se proclamaba en 1897 en el Círculo Católico zamorano ante ciento cuarenta obreros reunidos para festejar a la Inmaculada Concepción « ¿no es verdad que debemos unir todos nuestros esfuerzos para procurar la redención de esa sociedad amenazada y de esos pobres desgraciados por la fortuna? $\gg^{31}$. Esta redención de los obreros, la mejora de sus condiciones económicas y morales y el incremento de su bienestar serían el único modo de impedir que los trabajadores, postrados en la miseria, renegasen de Dios y se sublevasen ${ }^{32}$.

Sin embargo, la respuesta católica a la cuestión obrera no debía ceñirse a la mejora de las condiciones materiales, un propósito que podría conseguirse mediante determinadas instituciones, pues la misión de la Iglesia consistía en evangelizar. Por ello, la acción social católica debía pasar por la educación moral y religiosa de los obreros y, en este asunto, los líderes del catolicismo zamorano asumían como programa de acción el conocido lema del arzobispo de Valencia de $\ll$ Pan y catecismo» ${ }^{33}$. Era necesario, afirmaba unos de los redactores de El Correo de Zamora, «poner todos los medios conducentes a mejorar el estado moral de los trabajadores y al obrero se le moraliza enseñándole y para enseñarle es necesario contar con escuelas o círculos católicos» ${ }^{34}$. Con este propósito, en 1891 se había fundado el Círculo Católico de Zamora, el mismo año de la publicación de la encíclica Rerum novarum. Su creación era un fruto temprano del magisterio pontificio, pero también un paso más en la evolución de la beneficencia eclesiástica que se había volcado inicialmente en la actividad educativa. En 1883, casi una década antes de ser publicada la encíclica, el obispo Tomás Belestá había fundado en Zamora las Escuelas Dominicales y de Adultos con el fin de impulsar un programa de educa-

\footnotetext{
29 El Correo de Zamora, 10-12-1898.

30 El Correo de Zamora, 24-1-1903.

31 El Correo de Zamora, 9-12-1897.

El Correo de Zamora, 10-12-1898.

El Correo de Zamora, 31-12-1909.

34 El Correo de Zamora, 10-12-1898.
} 
ción popular de los obreros. Sin embargo, ahora se percibían otros riesgos vinculados al liberalismo por una parte y al socialismo por otra, que era preciso afrontar con nuevas instituciones. Esta conversión de las Escuelas Dominicales en Círculos Católicos de Obreros coincidente con la publicación de la encíclica mostraba un tímido paso de la beneficencia entendida en sentido clásico a un programa más amplio de la acción social católica que todavía estaba en mantillas.

\section{LA FUNDACIÓN DEL CÍRCULO CATÓLICO DE OBREROS DE ZAMORA (1891)}

Durante las últimas décadas del siglo XIX, en muchas localidades españolas se fundaron Círculos Católicos de Obreros cuyo precedente estaba en la actividad desarrollada por Albert de Mun y La Tour du Pin en Francia. Ambos líderes habían constatado la seducción que las ideas socialistas y comunistas ejercían sobre los obreros, cuya propaganda provocaba un distanciamiento e incluso una fuerte animadversión del proletariado contra la Iglesia. Tras conocer varias iniciativas sociales, ellos mismos pusieron en marcha los Círculos Católicos de Obreros, una estructura corporativista que integraba en su seno a trabajadores y empresarios con el fin de promover la armonía social y la reforma de las condiciones de los trabajadores mediante la moralización, la educación, el recreo y la acción económica de tipo cooperativo. No eran sindicatos, ni pretendieron serlo durante sus primeros años de existencia. No se constituyeron como una especie de movimiento obrero con conciencia de clase, tan solo se limitaron, en palabras de José Andrés-Gallego, «a sumar la tradición piadosa de las antiguas cofradías, la obra educativa de las Escuelas Dominicales y la labor económica de las Sociedades de Socorros Mutuos, aderezado todo ello con el recreo general que los Círculos tenían como finalidad primera $\gg^{35}$.

En España los primeros Círculos Católicos se fundaron en la cuenca mediterránea, gracias a la actividad de dos jesuitas conocedores del catolicismo social europeo: Antonio Vicent y Pablo Pastells ${ }^{36}$. El primero se fundó en Manresa en 1865, aunque la situación política y social del Sexenio Revolucionario paralizó su

35 José ANDRÉS-GALlEgO, La acción social y educadora de la Iglesia, en Bernabé BARTOLOMÉ MARTÍNEZ, Historia de la acción educadora de la Iglesia en España, vol. II (BAC maior, 54), Madrid, 1997, p. 847.

36 Rafael María SANZ DE Diego, El P. Vicent: 25 años de catolicismo social en España (1886-1912), en Hispania Sacra, 33 (1981), pp. 323-372. 
expansión. Con la llegada de la Restauración monárquica, el nuevo sistema político facilitó la difusión del catolicismo social y los Círculos Católicos adquirieron entonces expresiones muy variadas ${ }^{37}$. No obstante, durante los primeros años de la monarquía alfonsina, la gran cuestión que ocupó a los católicos fue la defensa de la unidad religiosa, por lo que las iniciativas sociales quedaron relegadas a un segundo plano ${ }^{38}$. Pasados los años, los Círculos Católicos se fueron implantando por diversos lugares de la geografía española. El padre Vicent quiso entonces que todas las fundaciones respondieran a un programa común y, por ello, el reglamento redactado en 1887 para el Círculo de Tortosa sirvió de modelo para la mayoría de los que se fundaron en España. Sin embargo, hasta 1893, fecha de celebración del primer Consejo Nacional de Corporaciones Católicas, no se contó con ninguna personalidad de relevancia en el ámbito nacional como la que ejerció el conde Mun en Francia. Esto hizo que los primeros Círculos comenzaran con modelos muy dispares, aunque posteriormente fueran coordinándose en un proyecto similar. El Consejo iniciaría la publicación de estadísticas en el año 1900, estadísticas a todas luces incompletas, pues de muchos Círculos no tenemos noticia ni de su existencia. De algunos sabemos que fueron fundados, pero no disponemos de más información acerca de su actividad y permanencia en el tiempo. Por los datos conocidos sabemos de la fundación de unos ciento cincuenta Círculos distintos, de los que treinta y dos contaban con caja de ahorros y nueve con cooperativa ${ }^{39}$.

En Castilla y León, una región donde el impacto de la industrialización fue débil, las asociaciones obreras católicas comenzaron por Burgos y Valladolid, donde se fundaron los primeros Círculos Católicos en 1883 y 1885 respectivamente ${ }^{40}$. El de Zamora se estableció en 1891 con la aprobación de sus estatutos, aunque su inauguración data del 6 de enero de $1892^{41}$. Su puesta en marcha contaba con el aliento del obispo, pero la idea y el impulso inicial partía del sacerdote Diego Luis Alonso, un clérigo diocesano que formó parte importante también en la reorganización de la comunión tradicionalista y en la fundación del diario carlista El Correo de Zamora ${ }^{42}$.

37 José Andrés-Gallego, Los Círculos de Obreros (1864-1877), en Hispania Sacra, 29 (1976), pp. 259-310.

38 Feliciano Montero, El eco de..., [ver n. 19], p. 433.

39 José ANDrÉs-Gallego, La Iglesia, en Historia de España y América, Madrid, 1983, p. 701.

40 Elena MaZa Zorrilla, Asociacionismo confesional en Valladolid: La Asociación Católica de Escuelas y Círculo de Obreros (1881-1914), en Investigaciones Históricas: Época Moderna y Contemporánea, 7 (1987), p. 178.

41 El reglamento de 1891 fue reformado en 1918 y en 1931: ZAMORA-ARCHIVO HISTÓRICO PROVINCIAL (=AHPZA), Gobierno Civil. Asociaciones, 9/33.

42 «Don Diego Luis Alonso», El Correo de Zamora, 14-12-1914. 
Su participación en el proyecto y la colaboración de algunos seglares vinculados al carlismo muestran la conexión temprana del tradicionalismo local con la incipiente acción social diocesana. El nuevo centro se puso bajo la protección de san Martín Cid, un santo vinculado a la historia local diocesana, y asumía la actividad de las Escuelas de Adultos que habían estado en funcionamiento durante una década ${ }^{43}$.

Es importante hacer notar aquí la prioridad cronológica de la acción social católica en la diócesis de Zamora respecto del movimiento obrero. En la literatura eclesiástica del momento el catolicismo social se presentaba como un muro de contención frente a la influencia del socialismo y del anarquismo, pero en ciudades como Zamora, esta acción social católica comenzaba sin la existencia organizada de su oponente ideológico. Las fechas son ilustrativas. En 1891 se fundó el Círculo Católico Obrero de la ciudad mientras que la Agrupación Socialista Zamorana no se constituyó hasta 1893 y las sociedades obreras no estuvieron organizadas hasta los primeros compases del siglo $\mathrm{XX}^{44}$. Aunque se ha subrayado que los Círculos Católicos tenían como objeto inmediato el de restar soldados al socialismo y extender la defensa social según el proyecto cristiano, en Zamora los inicios del movimiento obrero católico fueron más un antídoto o una prevención frente a lo que podía pasar con la difusión del socialismo que una respuesta ante lo que estaba ocurriendo en ese momento. Sin duda, en este asunto, las diferencias regionales nos exigen un análisis matizado de la acción social católica en España y evitar las generalizaciones ${ }^{45}$.

\section{SUS PRIMEROS AÑOS: «UN CENTRO DE MORALIDAD, INSTRUCCIÓN Y RECREO»}

Al día siguiente de su inauguración, el 7 de enero de 1892, ciento treinta obreros acudieron a las cátedras de Primera Enseñanza, Dibujo, Música, Geografía y Matemáticas que se ofrecían en el centro y que mantuvo su actividad docente durante más de medio siglo. Durante aquellos primeros años, el Círculo no pasa-

43 Boletín Eclesiástico del Obispado de Zamora, 30 (1892), pp. 22-23. Miguel Ángel HeRnÁNDEZ FUENTES, «Educar cristianamente a los obreros». Actividad educativa en la diócesis de Zamora durante la Restauración: las Escuelas de Adultos y el Círculo Católicos de Obreros, en Historia de la Educación, 36 (2017), pp. 253-276.

44 José Ignacio MARTÍN BENITO, Conflictos sociales en la provincia de Zamora a principios del siglo XX, en José Luis HeRnANDO GARRIDO (coord.), Necotium. Comercio e industria en Zamora XIX, XX, XXI, Zamora, 2007, p. 100.

45 José Manuel CuenCa TORIBIO, Catolicismo social... [ver n. 1]. 
ba de ser una versión actualizada de las Escuelas de Adultos que incorporaba en su sede un espacio para la recreación y la convivencia. Precisamente, la apuesta por fomentar la reunión y la sociabilidad fue una de las novedades que los Círculos aportaron a la acción social católica de finales del siglo XIX, en comparación con las Escuelas de Adultos precedentes. Como hacían otros grupos, estos centros católicos pretendían fomentar la concordia entre sus miembros y crear unos vínculos de pertenencia que los identificara con un proyecto concreto y un grupo determinado. En definitiva, se trataba de dar cohesión al grupo y fortalecer el «nosotros» comunitario ${ }^{46}$. Así lo hicieron otros movimientos sociales y políticos como los Círculos Tradicionalistas y los Centros Republicanos, cuya evolución resultó bastante paralela o las Casas del Pueblo impulsadas por los Socialistas ${ }^{47}$. De este modo, en el Reglamento reformado de 1931, el Círculo Católico Obrero de san Martín Cid se definía como «un centro de moralidad, instrucción y recreo para sus socios protectores y obreros inscritos» (art. 2), objetivo que se mantuvo cuarenta años después de la fundación y que presidió su actividad, especialmente durante los primeros años de funcionamiento:

El Círculo Católico, subordinándolos todos al supremo y último fin del hombre que es la mayor gloria de Dios y la salvación de las almas, persigue los siguientes fines: a) fin religioso, o sea la conservación de la fe y moralización cristiana de todos los asociados; b) fin instructivo, o sea la enseñanza literaria, científica y artística, basada en los principios católicos; c) fin recreativo dirigido a proporcionar a todos los socios saludable esparcimiento y honesto recreo (art. 5).

Para la consecución de estos fines se establecían unos medios de tipo religioso, instructivo, profesional y recreativo. Los primeros estaban coordinados por el consiliario y se centraban principalmente en la celebración de las fiestas religiosas, el entierro de sus socios y la oración por los difuntos. Con el propósito de ofrecer a los obreros una educación cristiana y una instrucción acomodada a su clase, se establecieron unas «escuelas y academias nocturnas en las que se enseñaba la doctrina cristiana, lectura, escritura, gramática, geografía e historia, aritmética, geometría aplicada a las artes, dibujo lineal figurado y de adorno, modelado y otras asignaturas» (art. 10). Con estas clases se pretendía instruir cultural y profesionalmente a los obreros y formarlos en el ejercicio de las vir-

46 Jordi CANAL, Banderas blancas, boinas rojas. Una historia politica del carlismo, 1876-1939, Madrid, 2006, p. 108.

47 Pedro Barruso, La sociabilidad en los espacios en el País Vasco (1900-1936). Casas del Pueblo y Círculos Obreros, en Vasconia, 33 (2003), pp. 207-222. 
tudes cristianas ${ }^{48}$. $\mathrm{Al}$ frente de ellas estuvieron diversos profesores que procedían del ámbito educativo de la capital como Gabriel Fuentes, pintor premiado en varias exposiciones regionales que disponía de una academia de Dibujo en Zamora ${ }^{49} \mathrm{o}$ el catedrático auxiliar de obras públicas Luis Gamboa ${ }^{50}$. Esta educación se completaba con una serie de conferencias que se ofrecían durante los domingos del prolongado invierno zamorano, constituyendo una de sus actividades más destacadas. En ellas se presentaban temas variados, principalmente religiosos, abordados desde una perspectiva social. No faltaron algunas conferencias acerca del magisterio social que suscitaban el entusiasmo de los trabajadores y los recelos de un determinado sector del clero ${ }^{51}$.

A partir de 1906, por un acuerdo de la junta directiva, se amplió el abanico de las materias que habían de impartirse en estas conferencias dominicales ${ }^{52}$, lo que, sin duda, aumentó su interés, atrayendo a una nutrida audiencia, especialmente cuando la charla era pronunciada por un conferenciante de renombre. Entre las materias abordadas ese año estaban «Las reglas de la aritmética», «La tuberculosis y los medios higiénicos de evitarla», «El ahorro» 0 «La importancia del arbolado ${ }^{53}$, temas que muestran una propuesta formativa que no se limitaba a la mera instrucción catequética. Para incentivar la lectura en los obreros, existía una biblioteca con revistas y periódicos católicos (art. $11^{\circ}$ ) y, para estimular su aprendizaje, se convocaban premios en certámenes de artes y oficios $\left(\operatorname{art.} 12^{\circ}\right.$ ), cuyos galardones se entregaban con motivo de las veladas literarias que tenían lugar en la fiesta de la Inmaculada, de san José o en la clausura del curso.

Esta apuesta de la Iglesia por la enseñanza de las clases populares no era una opción exclusiva del catolicismo, sino una necesidad social que también era demandada por los socialistas. En 1904 el presidente del Centro Obrero de Zamora, Ricardo Wamba reclamaba una mayor educación del proletariado, pues solo «el obrero instruido, podrá imponerse al patrón inhumano $»^{54}$. Poco después, la Federación de Sociedades Obreras convocaba sus conferencias con un programa que, en ocasiones, era semejante al del Círculo Católico ${ }^{55}$. $\mathrm{Al}$ año siguiente, el presidente del gremio de albañiles de Zamora se quejaba de que

\footnotetext{
48 El Heraldo de Zamora, 29-9-1900.

49 El Heraldo de Zamora, 26-9-1900.

50 El Heraldo de Zamora, 4-10-1902.

51 El Heraldo de Zamora, 4-5-1900.

52 El Heraldo de Zamora, 1906-10-29.

53 El Heraldo de Zamora, 29-10-1906, 24-11-1906, 15-12-1906 y 22-1-1907.

54 El Correo de Zamora, 26-4-1904.

55 El Heraldo de Zamora, 26-5-1904.
} 
el setenta y cinco por ciento de sus compañeros de oficio eran analfabetos, lo que hacía que el obrero fuese considerado por los burgueses como «un objeto, no una persona ${ }^{56}$. Como puede verse, socialistas y católicos coincidían en la necesidad de una instrucción adecuada que capacitase a los obreros para una mejora de su situación. Ambos señalaban al liberalismo como responsable de la miseria padecida por los obreros, pero se distanciaban en los fines y las acciones conducentes a superar este mal. En el caso del movimiento obrero se apostaba por la lucha sindical y en el caso de la Iglesia se defendía el mantenimiento del orden y de la armonía social.

Para el cumplimiento del fin recreativo, se habilitaron unos salones para el esparcimiento de los socios. Unos se utilizaban para aquellos juegos lícitos que habían sido aprobados por la junta directiva y otros para la celebración de actos públicos como veladas artísticas o literarias y funciones teatrales o cinematográficas. Con todas estas actividades se pretendía fomentar «la afición al Círculo y la mutua compenetración de todos los socios» (art. 14). En este sentido se cumplía con el objetivo antes mencionado de fomentar la cohesión social mediante la convivencia y la recreación. Sería interesante poder sondear la efectividad de este propósito, pero no disponemos de documentación suficiente para ello, aunque sabemos que el Círculo Católico Obrero tuvo una importante incidencia en la vida social de Zamora, siendo una de las instituciones que pesaban más en la representación institucional de actos eclesiásticos y civiles.

Respecto al sostenimiento económico, el Círculo se financiaba con la cuota de los «socios protectores», quienes aportaban sus donativos con la mentalidad paternalista propia del momento. Según los datos suministrados por el Obispado de Zamora, el Círculo Católico comenzó con 180 obreros y 243 contribuyentes $^{57}$. Sin embargo, tras unos inicios esperanzadores, los donantes disminuyeron e hicieron caso omiso de las reiteradas llamadas de la junta directiva: «nadie se ha movido para hacerse suscriptor, protestaba su presidente, se han repartido circulares, exponiendo la necesidad de recursos pecuniarios: nulo el resultado ${ }^{58}$. La cantidad recaudada en 1897 por las cuotas de sus socios quedaron reducidas a 173 pesetas mensuales con las cuales, según su director, era imposible sostener las enseñanzas impartidas a los doscientos obreros que acudían a las aulas. Esta carencia monetaria hizo que el obispado tuviera que apoyar económicamente las actividades del Círculo. En 1900, la enseñanza fue costeada totalmente por el

56 El Correo de Zamora, 1-5-1905.

57 Antonio VICENT, Socialismo y anarquismo, Valencia, 1895, p. 630.

58 Jesús Firmat, El Círculo Católico Obrero, en El Heraldo de Zamora, 11-12-1897. 
erario diocesano ${ }^{59}$ y durante años el propio obispo se encargó de financiar la Academia de Dibujo ${ }^{60}$. Con el deseo de colaborar al sostenimiento de una iniciativa social que reportaba ciertos beneficios a la ciudad, el Ayuntamiento comenzó a incluir en sus presupuestos anuales la cantidad de 250 pesetas destinadas a sostener económicamente la enseñanza, lo que muestra una vez más el carácter eminentemente instructivo del centro. Precisamente, esa era la condición que exigía el Consistorio a los establecimientos que aspirasen a percibir dicha subvención ${ }^{61}$.

Estas dificultades económicas nos permiten ofrecer una última valoración de la actividad desarrollada por el Círculo Católico que comenzó con notable entusiasmo y que, unos años después, languidecía por la falta de interés de los socios honorarios o de un proyecto social más ambicioso que superase la mera instrucción ${ }^{62}$. Esta falta de apoyo monetario era señalada por su director cinco años después de la fundación, una penuria que dificultaba la atención a los obreros, cuya asistencia se mantuvo en los dos centenares ${ }^{63}:$ «Es vergonzoso que el Círculo Católico de Obreros de Zamora esté sostenido solamente por los esfuerzos y la constancia de muy pocas personas: ¡en esta ciudad que se dice tan piadosa y tan cristiana!» ${ }^{64}$. Estas dificultades económicas eran puestas de manifiesto por la prensa local de uno y otro signo, donde se apoyaba el trabajo de este centro obrero confesional. Desde las páginas de El Correo de Zamora se reclamaba la colaboración activa de las Conferencias de san Vicente para sacar al Círculo Obrero de su postración, pues esta institución benéfica tenía más capacidad al disponer de más personal y de un volumen de actividad superior: « ¿Cuántos beneficios podría prestar la Conferencia de Zamora al Círculo Obrero de san Martín Cid, que, abandonado de todos, languidece de modo alarmante y desconsolador» ${ }^{65}$. También el diario liberal El Heraldo de Zamora expresaba el pesar de sus redactores por el declive de una institución dedicada a la educación de los obreros y señalaba algunas causas que impedían su desarrollo:

Educar cristianamente a los obreros, facilitar la mayor cultura general posible y la especial que convenga al oficio o arte a que se dediquen, ilustrar su entendimiento para que juzguen las cuestiones sociales, hoy tan discutidas con el criterio de rectitud y sensatez que nace de las enseñanzas de la Iglesia, es hacerles el mayor de los

\footnotetext{
59 El Heraldo de Zamora, 29-9-1900.

60 El Correo de Zamora, 5-5-1904.

61 El Heraldo de Zamora, 10-11-1910.

62 El Heraldo de Zamora, 5-4-1903.

63 Esta cifra se mantuvo con ligeras variaciones a lo largo de los años. Todavía en 1917 se contabilizaban 220 obreros que acudían a recibir la comunión general: El Correo de Zamora, 20-3-1917.

64 El Correo de Zamora 24-1-1902.

65 El Correo de Zamora, 1-4-1899.
} 
favores. La falta de entusiasmo propia de nuestro carácter, la crisis económica que atraviesa el país, y sobre todo el no haberse sentido hasta ahora los males sociales que en otras partes son formidable amenaza o terrible castigo, han hecho que por las clases acomodadas no se atienda todo lo debido a fomentar este remedio, el más eficaz para evitar aquellos males ${ }^{66}$.

$\mathrm{Al}$ margen de las razones señaladas, este texto pone de manifiesto algunas de las características que acompañaron a la actividad de los Círculos Católicos desde sus orígenes. La primera era el carácter prioritariamente instructivo del centro, pues hasta entrado el siglo XX, el Círculo no era más que una prolongación de las Escuelas de Adultos. La segunda era el paternalismo con que se entendía este tipo de actividades. Así lo había manifestado su director en el artículo antes citado, donde se pedía el apoyo económico de los pudientes zamoranos en favor de los menesterosos: «no olviden las clases acomodadas que la religión es el foco de las virtudes, la base de las costumbres públicas, consuelo de los afligidos y medio más eficaz que el amor de la patria para la conservación del orden social» ${ }^{67}$. Este apoyo económico al Círculo no solo era pedido por caridad, sino «para procurar el orden social», pues según su director, la participación de los obreros en las actividades del Círculo evitaría que las clases populares fueran víctimas de «nocivas doctrinas y perversas intenciones» que conducirían a la catástrofe como había ocurrido «en varias capitales de Europa ${ }^{68}$. Una vez más se percibe aquí la verdadera finalidad de estos centros católicos que se convertían en una alternativa a los males de la sociedad a que estaban sometidos los obreros. Por último, el artículo que estamos comentando, señalaba la escasa conflictividad obrera sentida en Zamora hasta la fecha, lo que sin duda contribuyó a retrasar una propuesta social católica más decidida en este campo. Unos años después, tras la llegada del siglo XX, el Círculo Católico superó esta crisis con el incremento de sus actividades, especialmente con la inclusión del mutualismo entre sus fines.

\section{LOS CAMBIOS EN LA ACCIÓN SOCIAL DIOCESANA AL COMENZAR EL SIGLO XX}

Tras una primera etapa del Círculo Católico de Obreros muy marcada por la pervivencia del propósito educativo que había guiado a las Escuelas de Adultos, los últimos años del siglo XIX trajeron consigo una serie de acontecimientos

66 El Heraldo de Zamora, 29-9-1900.

67 Jesús Firmat, El Círculo Católico... [ver n. 58].

68 Ibidem. 
que imprimieron un nuevo impulso a la acción social diocesana. Según Feliciano Montero, en este cambio influyeron la mayor recepción que la encíclica Rerum novarum tuvo a partir de la peregrinación obrera de 1894 en la que también participó Zamora ${ }^{69}$, la recepción madura del texto pontificio que se produjo en el congreso de Tarragona celebrado ese mismo año y la publicación del libro Socialismo y Anarquismo del padre Vicent, editado en Valencia en $1895^{70}$. Desde entonces, muchas obras sociales comenzaron a tomar unos rasgos distintivos con los que se pretendía transformar la acción social católica para hacerla más efectiva frente al liberalismo y al socialismo. En este sentido el debate que la encíclica fomentó en los años posteriores a su publicación contribuyó a una renovación de la cuestión social, poniéndola entre los temas más importantes del catolicismo finisecular. La celebración de los congresos católicos, la publicación de la Revista Católica de Cuestiones Sociales, la creación de la Consejo Nacional de las Corporaciones Católicas Obreras en 1896 fueron algunos de los ingredientes que facilitaron este debate $\mathrm{y}$ «dieron nueva importancia a la cuestión social» ${ }^{71}$.

Por su carácter agrario, en Zamora tuvo una mayor incidencia el congreso de Burgos, celebrado en 1899, donde los problemas del campo centraron gran parte del debate sobre la cuestión social. En él participaron algunos líderes carlistas locales como Luis Chaves, Francisco Morán o el director de El Correo de Zamora que formaron parte de la junta encargada de la difusión del congreso en la diócesis y lideraron la actividad del Círculo Católico. Precisamente en Zamora, al hilo de lo que ocurría en otros lugares de España, durante los últimos años del novecientos tuvo lugar el fortalecimiento del carlismo local, cuyos integrantes se implicaron notablemente en la acción social católica. Jordi Canal ha señalado la conflictividad que hubo entre los círculos carlistas y los católicos, especialmente en la España mediterránea ${ }^{72}$, pero como veremos más adelante, en Zamora la convergencia de intereses fue más que notable. La defensa del corporativismo que hicieron los tradicionalistas y su apuesta por el incremento de las sociedades cooperativas de producción y consumo ${ }^{73}$ les hizo especialmente activos en la fundación de las cajas rurales y de los sindicatos agrarios, pero también en la constitución de algunos Círculos Católicos de Obreros en diversas poblaciones de la diócesis y en la transformación del Círculo de la capital.

69 Miguel Ángel HeRnández Fuentes, En defensa de los sagrados intereses. Historia religiosa de la diócesis de Zamora durante la Restauración (1875-1914), Salamanca, 2016, pp. 758-759.

70 Antonio VICENT, Socialismo y anarquismo..., pp. 237-280.

71 William J. CALlaHAN, La Iglesia Católica en España (1875-2002), Barcelona, 2002, p. 108.

72 Jordi CANAL, Banderas blancas boinas rojas..., [ver n. 46], pp. 109-110.

73 Acta de Loredán..., [ver n. 24], p. 224. 


\section{CREación de otros Círculos Católicos EN la diócesis}

La llegada del siglo XX trajo consigo una mayor organización de los obreros. Como ya hemos señalado, durante los últimos años del siglo XIX el movimiento obrero en Zamora era muy débil y el Círculo Católico lideraba la respuesta social ante los problemas laborales. Sin embargo, tras la crisis finisecular las organizaciones obreras comenzaron a organizarse, lo que restaba trabajadores al proyecto católico. Aunque durante la primera década del siglo XX apenas hubo confrontación entre ambas propuestas, el crecimiento operado durante esos años por las asociaciones obreras precisaba de una respuesta católica más amplia, especialmente en el mundo rural donde el movimiento obrero tuvo un mayor arraigo ${ }^{74}$. Para responder a este desafío, durante los primeros años del siglo XX se fundaron otros Círculos Católicos por diversas poblaciones de la diócesis, de los cuales tan solo tuvieron cierta consistencia los de Villaralbo, Vezdemarbán, Madridanos, Vadillo de la Guareña y Toro.

El Círculo Católico de Villaralbo ya existía al comenzar el siglo XX, pues sus estatutos fueron presentados ante el Gobierno Civil en enero del año $1900^{75}$. Su creación fue impulsada por el sacerdote Manuel Jambrina, quien se encargó inicialmente de la enseñanza religiosa impartida a los obreros hasta su traslado a Zamora y la presidencia fue ejercida inicialmente por Julián Luelmo, párroco de Villaralbo, y poco después por el propietario Ángel Gallego González ${ }^{76}$. Sin duda, la presencia de la familia Luelmo en esta iniciativa social católica fue notable. Se trataba de una saga de agricultores y conocidos propietarios de la localidad que mantenían estrecho contacto con el carlismo provincial a quienes el diario tradicionalista los denominaba «sus correligionarios». Uno de sus más destacados miembros, Ángel Luelmo ejerció como presidente de la juventud carlista zamorana $^{77}$. En la actividad desarrollada por este Círculo siempre se subrayaba su carácter educativo, cuyo fin era, según sus promotores, «la instrucción religiosa y moralidad de la clase obrera ${ }^{78}$. A la luz de las escasas fuentes conservadas, estimamos que este Círculo no pasaba de ser una Escuela Nocturna impulsada por el párroco y por algunos notables propietarios de la villa, quienes, con un sentido paternalista, trataban de instruir a la masa de trabajadores con el fin de mejorar

\footnotetext{
74 Miguel Ángel Mateos RodrígueZ, La República en Zamora..., [ver n. 12], pp. 186-188.

75 El Heraldo de Zamora, 3-1-1900.

76 El Correo de Zamora, 10-12-1901.

77 El Correo de Zamora, 1-12-1899.

78 El Correo de Zamora, 3-11-1903.
} 
su educación, de apartarlos de las redes del caciquismo liberal y de alejarlos del peligro que podía suponer la difusión del socialismo. La docencia se impartía en la escuela de niños y a sus aulas acudían unos ciento veinte obreros. En 1913 más de cien asociados protestaron por la supresión de la enseñanza del catecismo en la escuela, lo que muestra la implicación de sus miembros en las actividades del Círculo durante más de una década ${ }^{79}$. En una localidad que superaba los mil cien habitantes, de los cuales 535 eran varones, quienes acudían al centro social católico representaban el veinte por ciento de la población, cifra que manifiesta un notable interés de los obreros por este proyecto social.

El de Toro fue fundado en 1907. En el mes de diciembre, el obispo Luis Felipe Ortiz, acompañado de Luis Chaves Arias y de Francisco Morán, se desplazó hasta Toro para presidir una velada de propaganda de la acción social católica. Acudían a esta población con la finalidad de fundar «las instituciones sociales que pareciesen más convenientes a las necesidades de la ciudad», entre las que figuraba «un Círculo Católico de Obreros que sirviese de punto de partida para el desarrollo de otras fundaciones ${ }^{80}$. Quedaron al frente de este centro dos abogados toresanos, Ángel Pérez Pinilla y Valeriano Enríquez que actuaron como presidente y secretario. Sabemos que el segundo era integrante del Partido Conservador y que participó en la política local consiguiendo una concejalía. Tras el acto de propaganda, el Círculo Católico de Toro abrió sus puertas en enero de $1908^{81}$, desarrollando una intensa actividad durante años sucesivos. Organizaba veladas especiales con motivo de la fiesta de san José y conferencias periódicas que seguían el modelo de lo que se hacía en Zamora. En 1910, dos años después de su fundación, un grupo de jóvenes trabajadores toresanos comenzó una campaña propagandística por la comarca para impulsar la creación de otros centros obreros confesionales, aunque poco sabemos de sus resultados ${ }^{82}$. No obstante, la existencia e implicación de la juventud local en este proyecto muestran la vitalidad del centro toresano que era capaz de movilizar a los jóvenes para la propaganda.

En 1909 se aprobaron los estatutos del Círculo Católico de Vezdemarbán ${ }^{83}$, que llegó a contar con doscientos socios en una población que apenas superaba los setecientos vecinos. Dos años después, en 1911, se fundaron los Círculos Ca-

79 El Correo de Zamora, 8-3-1913.

80 El Correo de Zamora, 4-12-1917.

81 El Heraldo de Zamora, 13-1-1908.

82 El Heraldo de Zamora, 25-11-1910.

83 ZAMORA-ARCHIVO HISTÓRICO DIOCESANO (=AHDZA), Cancillería, I/61. Expediente de aprobación de estatutos del Círculo Católico Obrero de Vezdemarbán 23-11-1909. 
tólicos de Vadillo de la Guareña ${ }^{84}$ y de Pajares de la Lampreana. Los estatutos de este último fueron aprobados en 1912 y tuvieron una vida efímera ${ }^{85}$. En 1916 ya había cesado su actividad, algo que no suponía un fracaso, sino la adaptación a los nuevos proyectos sociales. Ese año se fundó el Sindicato Católico Agrario que orientó la acción social católica hacia el sindicalismo agrario que tanto éxito tuvo por la comarca ${ }^{86}$. Lo mismo sucedió en otros pueblos, pues los Círculos Católicos respondían más a la cultura urbana y en el campo arraigaron mejor las cajas rurales y los sindicatos católicos agrarios que sustituyeron a los Círculos allí donde se habían fundado. También se estableció un Círculo Católico en Venialbo, cuyos integrantes buscaban en 1912 una ubicación para su sede ${ }^{87}$ y, más tarde, se fundó el Centro Obrero san Fernando en Peleas de Arriba, activo al menos desde $1913^{88}$. Como en el caso de Pajares de la Lampreana, en ambas localidades se fundaron sindicatos católicos agrarios en la segunda década del siglo XX y la actividad de sus Círculos quedó obsoleta ante el nuevo proyecto social católico en el mundo rural ${ }^{89}$.

\section{LA INCORPORACIÓN DEL MUTUALISMO Y DE OTRAS OBRAS SOCIALES}

Además de la finalidad educativa y recreativa a la que ya nos hemos referido, el Círculo Católico Obrero de Zamora tuvo también un carácter benéfico, aunque las estrecheces económicas padecidas desde finales del siglo XIX dificultaron la consecución de este fin ${ }^{90}$. Inicialmente, el objetivo se cumplía con la concesión de determinados premios y ayudas, pero con la llegada del nuevo siglo, comenzaron a desarrollarse otras actividades que implicaron una transformación de la beneficencia hacia proyectos basados en la previsión. José Andrés Gallego ha señalado el carácter católico de muchas de las iniciativas impulsadas por el reformismo social desde finales del siglo XIX y la contribución del catolicismo

84 AHPZA, Gobierno Civil, Asociaciones. Libro registro de asociaciones, no 176.

85 AHDZA, Cancillería, J/46. Círculo Católico de Pajares de la Lampreana 1912.

86 AHDZA, Cancillería, L/112. Expediente de aprobación de los estatutos del Sindicato Agrícola y de la Caja Rural de Crédito de Pajares de la Lampreana 1913.

87 AHDZA, Cancillería, L/126.

88 AHDZA, Gobierno Civil, Asociaciones. Libro registro de asociaciones, $\mathrm{n}^{\circ} 260$.

89 AHDZA, Cancillería. P/Valdegema 31 y 14.

90 En una carta el presidente del Círculo Católico de san Martín se mostraba la situación financiera deficitaria pues se debían 202 pesetas y no se habían podido ni siquiera entregar los premios a los alumnos del año anterior: AHDZA, Secretaría de Cámara, caja 368. Carta del presidente del Círculo Católico de san Martín al obispo Luis Felipe Ortiz, Zamora, 21-VI-1899. 
social a la institucionalización del ahorro, a la configuración del mutualismo y a la articulación de una red crediticia ${ }^{91}$. Algunas de estas iniciativas se incorporaron al Círculo Católico, contribuyeron a su sostenimiento y a renovar el interés de los afiliados por un proyecto que les permitiría hacer frente a diversas situaciones de calamidad, evitando una dependencia excesiva de las obras de caridad. La implicación de los líderes carlistas locales fue capital en este asunto como veremos más tarde.

En 1901, Luis Chaves Arias presentó el proyecto de creación de una Caja de Socorros Mutuos y, tras el visto bueno de los miembros del Círculo, sus estatutos fueron llevados al Gobierno Civil para su aprobación ${ }^{92}$, poniéndose en marcha ese mismo año ${ }^{93}$. La finalidad de esta caja consistía, según el último reglamento aprobado, en proporcionar una pensión o socorro diario a los asociados enfermos y facilitarles asistencia facultativa y medicinas. En caso de fallecimiento se entregaba una cantidad a la viuda o a los padres si el asociado estaba soltero. Asimismo, se asignaba un socorro pecuniario a las madres durante los veinte días siguientes al parto y se constituyeron pensiones de retiro a favor de los asociados. Los socios debían ser todos obreros residentes en la ciudad o en el entorno y pertenecer al Círculo Católico. Su creación atrajo a un importante número de obreros como se desprende del conflicto desatado en 1910 por ciertas desavenencias acerca de los servicios prestados por el médico que provocó el abandono de cuarenta socios ${ }^{94}$. $\mathrm{Al}$ margen del alcance que tuvo esta polémica, de la que apenas tenemos más detalles, los cuarenta socios que abandonaron la institución por desavenencias con el resto indican la existencia de un notable número de miembros y el interés que los obreros manifestaban por el mutualismo, que fue uno de los motivos del éxito y de la pervivencia del Círculo Católico una vez entrado el siglo XX.

El proyecto de fomentar la obra social no se limitó a la creación de sociedades de socorros mutuos, sino de otras instituciones crediticias y benéficas. En una conferencia pronunciada ante los obreros inscritos en la Caja de Socorros $\mathrm{Mu}-$ tuos de Zamora, Luis Chaves Arias recordaba que León XIII había recomendado principalmente tres obras sociales: las cajas rurales, los secretariados del pueblo y las casas y huertos para obreros ${ }^{95}$. Respecto a las cajas rurales, Luis Chaves se

\footnotetext{
91 José Andrés-Gallego, Pensamiento y acción... [ver n. 5], p. 408.

92 El Heraldo de Zamora, 27-2-1901. Los estatutos fueron aprobados oficialmente en 1906, reformados en 1918 y nuevamente en 1931, AHPZA, Gobierno Civil, Asociaciones. 5/18.

93 El Heraldo de Zamora, 18-3-1901.

94 El Heraldo de Zamora, 31-1-1910.

95 El Correo de Zamora, 24-1-1903.
} 
convirtió en un importante promotor de estas entidades crediticias, cuyas primeras fundaciones en Zamora datan del año 1901. Comenzó por pueblos como Moraleja del Vino y Arcenillas, pero, a finales de ese mismo año, se constituyó también una Caja Rural en la ciudad de Zamora ${ }^{96}$. Aunque estaba destinada a los agricultores, cuyos préstamos debían destinarse a las atenciones reproductivas del cultivo agrícola, Chaves buscaba la manera de introducir en ellas algunas modificaciones con el fin de «adaptarlas en su beneficio a los obreros de las ciudades ${ }^{97}$.

En cuanto a la tercera obra social señalada por el papa, Chaves trató de impulsar en Zamora la creación de una sociedad constructora de casas para obreros titulada «La casa y el huerto del obrero». Con ello trataba de aplicarse a la ciudad un modelo habitual en el siglo XIX que consistía en mejorar las condiciones de habitabilidad de los trabajadores conforme a los planteamientos higienicistas del momento. Algunos han señalado también el trasfondo político subyacente a este planteamiento sanitario, pues si los trabajadores vivían en lugares dignos y se lograba que fueran propietarios, se amortiguarían los brotes revolucionarios ${ }^{98}$. En Zamora este modelo fue puesto en práctica en 1885 con la expansión del barrio de Pantoja promovido por el Ayuntamiento y en 1894, cuando Candelaria Ruiz del Árbol, una acaudalada mujer de la ciudad, construyó unas casas para los obreros desde un planteamiento caritativo que nacía de su fe católica. En 1903, el mismo año en que se creó el Instituto de Reformas Sociales, Chaves presentó en el Círculo Católico de Zamora su proyecto para construir viviendas obreras en la ciudad. Este activista católico deseaba su implantación en Zamora y, para ello, Toribio Gimeno Bayón redactó los estatutos ${ }^{99}$, se constituyó una sociedad anónima y se nombró una junta integrada por él mismo y por otros colaboradores del Círculo Católico ${ }^{100}$. El proyecto no pudo materializarse, pero cuatro años más tarde, el alcalde Isidoro Rubio planeó, en 1907, la construcción de un barrio de casas para los trabajadores. Los detalles de este proyecto, que nunca llegó a ver la luz, han sido relatados por Álvaro Ávila de la Torre, quien subraya el conocimiento que Luis Chaves tenía de la economía y del pensamiento político del siglo XIX y su implicación en la defensa de los trabajadores frente a un proyecto municipal que no era nada ventajoso para los obreros ${ }^{101}$.

\footnotetext{
96 El Correo de Zamora, 10-1-1902.

97 El Correo de Zamora, 24-1-1903.

98 Álvaro ÁvILA DE LA TORRE, Arquitectura y urbanismo en Zamora (1850-1950), Zamora, 2009, p. 575.

99 El Correo de Zamora, 24-1-1903.

100 El Correo de Zamora, 16-2-1903.

101 Álvaro ÁvILA DE LA TORRE, Arquitectura y... [ver n. 98], p. 579.
} 


\section{PRINCIPALES AGENTES Y PROMOTORES DE LA ACCIÓN SOCIAL DIOCESANA}

La ausencia de congregaciones masculinas en Zamora hizo que los Círculos estuviesen vinculados directamente con el Obispado zamorano. La creación del Círculo de la capital fue una iniciativa del obispo Tomás Belestá, que ya había manifestado su interés en la constitución de las Escuelas Dominicales y de Adultos puestas bajo la tutela de algunos docentes de la Escuela Normal y de los profesores del Seminario. No existía influencia directa de ninguna congregación religiosa en ellas, salvo su proyecto, que fue copiado de otras latitudes donde operaban los jesuitas o los dominicos. La llegada a Zamora del obispo Luis Felipe Ortiz y la reorganización del carlismo local operada durante la última década del siglo XIX trajeron consigo una notable influencia de los dirigentes tradicionalistas en la acción social católica. Este grupo mantuvo abierto durante años un Círculo Tradicionalista en la capital, sostuvo un periódico, El Correo de Zamora, como medio de expresión y consiguió colocar a sus representantes políticos tanto en el municipio como en la Diputación.

Entre los miembros destacados del carlismo que estuvieron al frente del Círculo Católico de Obreros podemos contar a Fernando Canillas que fue su presidente hasta 1906 en que murió ${ }^{102}$ o a Francisco Morán que le sucedió hasta 1912. El primero era médico de la beneficencia municipal y estuvo significado en otros proyectos católicos de corte más religioso como la Asociación del Culto Continuo o la Adoración Nocturna ${ }^{103}$. El segundo era catedrático de Griego en el Seminario diocesano y un destacado erudito local que, en 1905, obtuvo un puesto en la Diputación provincial representando al carlismo. Según su oponente liberal, El Heraldo de Zamora, el prestigio que tenía este ilustrado tradicionalista le permitió cosechar un gran número de sufragios, triunfando holgadamente sobre el resto de candidatos tanto en la capital como en la provincia ${ }^{104}$. En 1909 le sucedió como candidato a diputado provincial Ángel Luelmo Avedillo quien también colaboraba en la marcha del catolicismo social y se presentaba a este escaño con el propósito de defender los intereses católicos ${ }^{105}$.

102 Sucedía a Jesús Firmat y Cabrero, un católico de relevancia en la ciudad que presidió el Círculo Católico durante sus primeros años y, aunque no se declaraba carlista, mantenía una postura lejana de los planteamientos liberales con cuyo órgano de expresión polemizó: El Correo de Zamora, 24-3-1897.

103 Miguel Ángel HeRnÁNDEZ Fuentes, La comunión reparadora... [ver n. 23], pp. 172-173.

104 El Heraldo de Zamora, 13-3-1905.

105 El Heraldo de Zamora, 12-10-909. 
También eran carlistas el secretario del Círculo Católico, Juan Gil Angulo, que había estado al frente de la secretaría de la Juventud Carlista o Luis Chaves Arias que era uno de sus líderes más conocidos en la provincia y fuera de ella. Chaves ejerció como vicepresidente de la Junta Provincial Carlista hasta 1903 en que asumió la presidencia durante los seis años siguientes ${ }^{106}$. Aunque este apóstol del catolicismo social ha sido más conocido por su labor de implantación y difusión de las Cajas Rurales, Luis Chaves estuvo notablemente implicado en la marcha del Círculo Católico de Zamora donde se encargó de la constitución de una Sociedad de Socorros Mutuos y de la promoción de casas para obreros. Los actos de propaganda desarrollados en Toro y en otras localidades fueron impulsados por algunos de los miembros del tradicionalismo y al frente del Círculo Católico de Villaralbo también estuvieron algunos carlistas como los integrantes de la familia Luelmo, ya citados, o el maestro del pueblo, Dionisio Pereda que asumió parte de la docencia.

Médicos de la beneficencia municipal y maestros que colaboraban con el centro como parte de una vida dedicada a la asistencia social y a la educación; propietarios agrícolas que se veían desplazados por el nuevo sistema liberal; abogados y políticos que defendían un proyecto en el que coincidían como católicos y tradicionalistas o integrantes de la burguesía comercial de una ciudad poco involucrada en la industrialización eran los auténticos motores del Círculo Católico de Obreros, quienes engrosaban mayoritariamente las filas del tradicionalismo local. Ellos ocupaban no pocas parcelas de la vida social y económica de la ciudad y ejercían un notable influjo sobre determinadas capas de la población, aunque sin la fuerza suficiente para hacer frente al caciquismo que denunciaban e incapaces de convertirse en una alternativa frente a la hegemonía ejercida por determinadas familias liberales ${ }^{107}$.

Cierto que no todos los promotores del catolicismo social eran carlistas, pero sí una buena parte, lo que marca una convergencia de ideales entre el proyecto tradicionalista y el magisterio social católico que se invocaba frecuentemente en las páginas de El Correo de Zamora ${ }^{108}$. El diario reafirmaba la fidelidad de los carlistas al magisterio de León XIII ${ }^{109}$, remarcaba la necesidad de educar a

\footnotetext{
106 El Correo Español, 23-11-1909.

107 José Ramón MiLÁN GARCÍA, Liderazgo nacional y caciquismo local: Sagasta y el liberalismo zamorano, en Ayer, 38 (2000), p. 239.

${ }^{108}$ La cuestión obrera y los católicos, en El Correo de Zamora, 19-2-1903.

109 Enseñanzas de León XIII sobre la cuestión social, en El Correo de Zamora, 5-3-1903; León XIII y los obreros, en El Correo de Zamora, 23-7-1903.
} 
los trabajadores ${ }^{110}$ y reclamaba la obligación que los cristianos tenían de socorrer a los obreros, procurándoles su bienestar con el fin de impedir que, postrados en la miseria, renegasen de Dios y se sublevasen ${ }^{111}$. Como puede verse, la participación de los carlistas en las obras sociales católicas fue más que notable, lo que supuso la ampliación de sus bases sociales entre los jóvenes y las clases populares $^{112}$. La ideología del carlismo, construida sobre la unidad religiosa de la nación española, su colaboración con la acción social católica y su implicación en diversas asociaciones piadosas los ponía en la vanguardia de la militancia confesional, especialmente durante el pastoreo del obispo Luis Felipe Ortiz que coincidía con el rearme del carlismo ${ }^{113}$. Tras su muerte, la llegada a Zamora de monseñor Antonio Álvaro Ballano en 1914, supuso el inicio de otros tiempos en los que el nuevo prelado mitigó bastante el protagonismo de este colectivo. Muestra de este deseo de marcar distancia con el tradicionalismo local fue el incidente ocurrido con El Correo de Zamora, que fue rescatado económicamente por el Obispado a condición de retirar su apelativo de diario tradicionalista, manteniendo en su cabecera tan solo el subtítulo de diario católico ${ }^{114}$.

\section{EL MOVIMIENTO OBRERO Y LA ACCIÓN SOCIAL CATÓLICA}

Ya hemos señalado que el desarrollo del movimiento obrero en Zamora es bastante tardío respecto a otras latitudes y comenzó unos años después de la creación del Círculo Católico. En 1893 se fundó la Agrupación Socialista Zamorana y a finales del siglo XIX circulaban varios periódicos obreros que contribuyeron a crear una mentalidad de clase entre los trabajadores. Fue a partir de 1898, tras la carestía producida por la crisis finisecular, cuando la movilización obrera se hizo más frecuente y se produjeron algunos motines y manifestaciones contra la saca de trigo ${ }^{115}$. Esta incipiente organización del proletariado zamorano tuvo

110 El Correo de Zamora, 31-12-1909.

111 El Correo de Zamora, 10-12-1898.

112 María Pilar SALOMÓN CHÉLIZ, Entre el insurreccionalismo y el posibilismo. Las culturas políticas del catolicismo español (1875-1936), en La Restauración y la República, 1874-1936, Zaragoza, 2015, p. 318.

113 Jordi CANAL, Banderas blancas boinas rojas..., [ver n. 46], pp. 171-173.

114 Miguel Ángel HeRNÁNDEZ FuENTES, «El Correo de Zamora». Confesión religiosa y orientación política de un diario tradicionalista (1897-1916), en Investigaciones históricas. Época moderna y contemporánea, 37 (2017), pp. 421-452.

115 José Ignacio MARTín Benito, Conflictos sociales... [ver n. 44], p. 100. 
un primer desarrollo en el noreste de la provincia y estuvo muy vinculado a las sociedades obreras del campo que mantenían contacto con las zonas mineras de Vizcaya o la Rioja ${ }^{116}$. También algunos pueblos ubicados al sur de la capital experimentaron la movilización obrera con motivo de la crisis de subsistencia que reinó en torno a 1900. Así ocurrió en Coreses o en Moraleja del Vino, donde las mujeres salieron a la calle para pedir pan y trabajo. Esta movilización espontánea o coordinada con motivo de la carestía trajo consigo la constitución de las primeras agrupaciones obreras en algunos pueblos de la comarca del Vino como Moraleja, Corrales o Villanueva de Campeán. Esta última fue una de las más tempranas y activas de cuya existencia tenemos noticia durante la primera década del siglo XX con una afiliación que osciló entre los dieciséis y los cuarenta y siete trabajadores ${ }^{117}$.

En 1903 sabemos de la existencia de una Federación de Sindicatos que agrupaba a cinco gremios de trabajadores: albañiles, carpinteros, hortelanos, zapateros y metalúrgicos que contaban con un centro de reunión y propaganda. Ese mismo año, los miembros de las sociedades obreras concurrieron a las elecciones municipales con dos candidatos lo que implicaba una cierta capacidad de organización, aunque con escasos resultados. Los republicanos querían acudir a las urnas junto a los obreros, pero, tras un acalorado debate, estos rehusaron acudir unidos a los comicios ${ }^{118}$. Ciertamente, el sistema no favorecía su victoria, pero tampoco la de otros grupos minoritarios que, sin embargo, obtuvieron una significativa representación municipal como los carlistas. Los años de carestía impulsaban las reivindicaciones obreras, pero estas se desinflaban en los años sucesivos. Tras la crisis padecida en los primeros años del siglo XX, la afiliación a la UGT en la provincia creció hasta sumar trece secciones y mil trabajadores en marzo de 1905. Este abultado incremento se producía principalmente en el nordeste de la provincia en un territorio que no pertenecía al obispado de Zamora y ajeno por tanto a nuestro estudio. Sin embargo, siete meses más tarde, los militantes se habían reducido a la mitad y en 1908 tan solo estaban afiliados en el sindicato unos sesenta trabajadores de una sección ${ }^{119}$. Esa situación se mantuvo

116 ID, Crisis obrera y conflictividad social en el nordeste zamorano (1898-1920). El periodo 1898-1905 y la implantación del socialismo, en Brigecio, 8 (1998), pp. 211-240.

117 Javier RodrígUEZ GONZÁLEZ, La difícil andadura inicial (1888-1909), en Manuel REDERO SAN Román (ed.), La Unión General de Trabajadores en Castilla y León (1888-1998), León, 2004, p. 88-96. 118 El Correo de Zamora, 16-10-1903.

119 Javier RodRÍGUEZ GONZÁLEZ, La difícil andadura..., [ver n. 117], p. 39. 
hasta concluir el periodo que nos ocupa, cuyos datos muestran una afiliación a la UGT de cien trabajadores pertenecientes a dos secciones en $1910^{120}$. Aunque la escasez de fuentes nos impide tener un número preciso de los integrantes del movimiento obrero y de quienes formaban parte del catolicismo social, ya hemos señalado que el Círculo Católico de Zamora acogía por esas mismas fechas entre cien y doscientos trabajadores y otro centenar participaban en el de Villaralbo o en el de Vezdemarbán.

Para impulsar el movimiento obrero, en 1904, Pablo Iglesias visitó la ciudad durante su gira por las provincias de Zamora, Valladolid, Palencia y León ${ }^{121}$. Según relataba El Heraldo de Zamora, en el mitin pronunciado en el colegio de los Descalzos había una escasa presencia de obreros y una total ausencia de agricultores $^{122}$. En ello coincidía con El Socialista que subrayaba una participación notable de burgueses y de hombres de carrera ${ }^{123}$. Su discurso se centró en la lucha por mejorar las condiciones de la clase proletaria, invitando a los asistentes a constituir sociedades de resistencia frente a los patronos. Pero este líder del movimiento obrero también se explayó en críticas la burguesía, a los republicanos y formuló algunos ataques a la religión católica y a sus ministros afirmando que los elementos clericales «como todos los demás soportes de la burguesía serán anulados por el socialismo» ${ }^{124}$. $\mathrm{Al}$ margen de esta crítica, apenas tenemos constancia de la existencia de conflictos entre el programa socialista y el proyecto social católico. Aunque el anticlericalismo anidaba en muchas publicaciones defensoras de la clase obrera, en Zamora no se vivía la tensión observada en otras latitudes, al menos, durante los primeros años de expansión del movimiento obrero. Ciertamente este tenía una escasa organización en la provincia y un carácter escasamente reivindicativo. Su presencia se hacía más palpable en momentos coyunturales en que hubo crisis de subsistencia, por lo que sus peticiones no solían teñirse de contenido político sino que resaltaban las difíciles condiciones de vida padecidas por los trabajadores y reclamaban un jornal capaz de hacer frente a la inflación ${ }^{125}$.

${ }^{120}$ José Luis Martínez CELADA, Crecimiento y consolidación (1910-1930), en Manuel Redero SAN ROMÁN (ed.), La Unión General... [ver n. 117], p. 101.

121 El Socialista, 7-10-1904.

122 El Heraldo de Zamora, 7-11-1904.

123 El Socialista, 18-10-1904.

124 El Socialista, 18-11-1904.

125 María Paz Corredera y Josefina Cuesta, Historia de la acción social..., [ver n. 14], p. 542. 
El diario católico tradicionalista por su parte valoraba positivamente la actitud de los trabajadores de la provincia con motivo de la celebración del primero de mayo de 1904 y elogiaba «la sensatez y cordura de los obreros zamoranos que sin grandes alharacas y estrepitosas manifestaciones prosiguen su camino con dignidad, exponen sus deseos sin altanería pero también sin humillación y con sus actos se hacen acreedores al respeto de todos ${ }^{126}$. Las relaciones de muchos de los integrantes de las sociedades obreras de Zamora debían de ser cordiales con la Iglesia. Según El Socialista, en Villanueva del Campeán, donde radicó uno de los sindicatos más tempranos, el párroco bendijo en 1904 el féretro de un obrero cubierto con la bandera ${ }^{127}$. Ese mismo año, un canónigo de la catedral se encargaba de impartir las conferencias económico-populares en el Centro Obrero de albañiles y carpinteros de Zamora ${ }^{128}$. Esto nos hace pensar que la confrontación estaba más en el ideario que en las personas y que la pugna venía dada por las consignas llegadas desde otras latitudes, mucho más vinculadas al republicanismo anticlerical o al anarquismo. Ya algunos autores han señalado la ausencia de un discurso anticlerical durante las primeras décadas del movimiento obrero ${ }^{129}$ y la distancia inicial de Pablo Iglesias respecto al anticlericalismo, pero también su cambio de postura a partir de 1899 en que afirmó la incompatibilidad entre la Iglesia y el socialismo ${ }^{130}$. Cierto que en su periplo por los pueblos de Zamora el líder socialista utilizó algunas consignas anticlericales y que estas fueron aplaudidas por algunos miembros del auditorio, pero en las páginas del diario católico tradicionalista se hacía una lectura benigna de la actividad promovida por ambos conferenciantes, Remigio Cabello y Pablo Iglesias:

Como era de esperar, uno y otro condenaron que se acudiese a procedimientos de violencia más que en caso de necesidad y recomendaron a todos los obreros la federación. El compañero Cabello expuso en su discurso las reglas prácticas a que debía ajustarse la conducta de los obreros y Pablo Iglesias explicó el ideal socialista y cómo podríamos llegar a la extinción del capitalismo, a la abolición de clases y a la igualdad de todos en el trabajo. La belleza del ideal no consiguió entusiasmar al

126 El Correo de Zamora, 2-5-1904.

127 El Socialista, 22-1-1904.

128 El Correo de Zamora, 30-11-1904.

129 Manuel SUÁREZ CORTINA, Clases populares, republicanismo y anticlericalismo en la España del primer tercio del siglo XX, en Julio de la CUEVA y Feliciano MONTERO (eds.), Izquierda obrera y religión en España (1900-1939), (Obras colectivas Humanidades, 29), Alcalá de Henares, 2012, pp. $40-41$.

130 Víctor Manuel ArbelOA, El partido socialista y la Iglesia (1879-1925), a través de Pablo Iglesias, en Julio de la CUEva y Feliciano MONTERO (eds.), Izquierda obrera..., [ver n. 129], pp. 53-54. 
auditorio; en cambio no faltó quien aplaudiera las declaraciones anticlericales del leader, que fue la nota grotesca de su discurso. El acto terminó con el mayor orden y sin que hubiera que lamentar el más pequeño incidente ${ }^{131}$.

Fue durante la segunda década del siglo Xx, especialmente a partir de la Semana Trágica de Barcelona, cuando las cosas cambiaron y cuando la confrontación entre católicos y socialistas se hizo más habitual. La conjunción republicano-socialista trajo consigo un rechazo más virulento del sindicalismo católico por parte de los socialistas y la asunción de un discurso anticlerical. No faltaron entonces los conflictos en algunos pueblos de Zamora a los que nos hemos referido en otro lugar ${ }^{132}$. Además, al comenzar la segunda década del siglo XX la acción social católica se puso en marcha de un modo más coordinado y la pugna entre ambos modelos, el confesional y el socialista, vivió una etapa de mayor tensión. La lectura benévola que El Correo de Zamora hacía de la conmemoración del primero de mayo de 1904 y de los años sucesivos fue sucedida por una fuerte crítica respecto de la que tuvo lugar en 1912. En esta ocasión, los redactores del periódico tradicionalista señalaban que la obra de teatro representada durante la noche anterior suponía un escarnecimiento de «la Iglesia en sus dogmas y en sus instituciones» y que, durante los discursos pronunciados tras la manifestación, hubo ataques «a la burguesía y (¡como no!) al clero» ${ }^{133}$. El diario se quejaba por la pasividad de las autoridades que habían permitido el acto, lo que motivó la respuesta de El Socialista defendiendo a los trabajadores zamoranos ${ }^{134}$. El mismo año en que se producían estas tensiones, comenzaba a publicarse en Zamora un periódico titulado La Voz del Pueblo que se presentaba como el órgano de expresión del partido republicano y pretendía convertirse también en portavoz de la clase obrera dada la conjunción entre ambas fuerzas que se produjo durante esos años. En sus páginas se notaba el giro de los socialistas hacia una mayor beligerancia anticlerical ${ }^{135}$. Eran nuevos tiempos, donde la contraposición entre el obrero católico y el obrero «rojo» comenzaron a ocupar buena parte de la publicística del momento ${ }^{136}$.

${ }^{131}$ El Correo de Zamora, 2-5-1904.

132 Miguel Ángel HeRnÁndeZ Fuentes, En defensa... [ver n. 69], pp. 791-793.

133 Osadías socialistas, en El Correo de Zamora, 1-5-1912.

134 Zamora, perdida en una hora, en El Socialista, 17-5-1912.

135 Miguel Ángel HERNÁNDEZ FuENTES, «Velar por la fe y las costumbres». Censura eclesiástica sobre la prensa zamorana durante la Restauración, en Revista Internacional de Historia de la Comunicación, 6 (2016), pp. 61-81.

136 El Correo de Zamora, 20-3-1917. 


\section{CONCLUSIONES}

Tras un estudio detallado de los primeros años de funcionamiento del Círculo Católico de Zamora podemos extraer algunas conclusiones que atañen a su primera etapa de vida. La primera es la íntima vinculación del Círculo con la actividad desempeñada por las Escuelas de Adultos que se implantaron en Zamora durante la Restauración. El Círculo Católico de la capital y sus homónimos de Toro y Villaralbo fueron considerados en su primer estadio de funcionamiento como unos centros de educación y moralidad. La Iglesia confiaba en el papel reformador de la educación cristiana y esperaba que la instrucción popular y la formación moral y religiosa serían suficientes para mejorar las condiciones de los trabajadores. Este proyecto fue exitoso en cuanto a respuesta de los trabajadores, pero se desveló como insuficiente para lograr su propósito, especialmente durante los primeros años del siglo XX en que los trabajadores comenzaron a organizarse bajo la bandera socialista. Esta circunstancia trajo consigo una adaptación ante los nuevos retos que nos aporta una segunda conclusión: los Círculos Católicos no eran unas instituciones monolíticas sino cambiantes, que se acomodaron a los nuevos desafíos.

Esta evolución se produjo ante algunos acontecimientos externos como el crecimiento del movimiento obrero, la inclusión de un programa reformista por parte del conservadurismo español o la asunción de la doctrina social de la Iglesia por los líderes carlistas; pero también por un lento proceso de asimilación y puesta en práctica en la diócesis del magisterio social pontificio. En este itinerario, la llegada del siglo XX trajo consigo una ampliación de actividades por parte del Círculo Católico que pasó de ser un centro educativo donde se fomentaba la convivencia y la recreación como medio para fortalecer el sentido de pertenencia, a convertirse en un centro promotor y coordinador de diversas entidades de ahorro, mutualidad y previsión.

La tercera conclusión que podemos extraer es la escasa conflictividad inicial con las sociedades obreras. Sin bien la propuesta cristiana era alternativa al proyecto socialista, hasta la segunda década del siglo XX apenas se percibe en Zamora la confrontación entre ambos modelos. La debilidad del movimiento obrero zamorano durante los primeros años del novecientos, lo esporádico del discurso anticlerical entre los socialistas y la consideración del liberalismo como el enemigo común de ambas propuestas hicieron que el movimiento obrero y la acción social católica fueran considerados en la ciudad como modelos alternativos, pero no antagónicos. En un segundo momento, el crecimiento de las sociedades obreras, la asunción de un discurso más beligerante contra la Iglesia 
por parte de sus líderes y la mejor organización del catolicismo social trajeron consigo una mayor confrontación entre el modelo católico y la propuesta socialista.

Por último, el estudio revela la importante implicación de los laicos en el proyecto social del catolicismo zamorano. Las escuelas dominicales fueron una iniciativa episcopal que contó con el apoyo de los docentes seglares y en esta misma línea seguía el Círculo Católico de Obreros durante sus primeros años de actividad. Sin embargo, al comenzar el siglo XX el protagonismo de los laicos fue capital en el desarrollo de la acción social católica. Conocedores de lo que estaba ocurriendo en otros lugares, fueron ellos quienes impulsaron y promovieron las diversas iniciativas sociales. Además, entre los seglares zamoranos, quienes más se significaron fueron los líderes carlistas que disponían de un periódico y de un centro de reunión y propaganda y obtuvieron representación municipal. Su programa de acción recogido en el acta de Loredán coincidía a grandes rasgos con el programa de acción social católica que implantaron en la ciudad con diversas iniciativas de tipo corporativo. 
